\title{
HIGH ACCURACY DATA REPRESENTATION VIA SEQUENCE OF NEURAL NETWORKS
}

\author{
B PALÁNCZ $Z^{1}$ and L VÖLGYESI ${ }^{2}$
}

[Manuscript received June 11, 2002]

\begin{abstract}
Sequence of neural networks has been applied to high accuracy regression in $3 \mathrm{D}$ as data representation in form $z=f(x, y)$. The first term of this series of networks estimates the values of the dependent variable as it is usual, while the second term estimates the error of the first network, the third term estimates the error of the second network and so on. Assuming that the relative error of every network in this sequence is less than $100 \%$, the sum of the estimated values converges to the values to be estimated, therefore the estimation error can be reduced very significantly and effectively. To illustrate this method the geoid of Hungary was estimated via RBF type network. The computations were carried out with the symbolic - numeric integrated system Mathematica.
\end{abstract}

Keywords: geoid, neural networks.

\section{Introductions}

Measured data structure representation frequently carried out by interpolation or regression. In case of $2 D$, it means the approximation of a surface. These techniques may be used on regular grid or irregular grid employing Delaunay triangulation. For global data representation, when the number parameters of the trial function to be determined is considerably less than the number of the measured points, algebraic or trigonometric polynomials may be applied. Such models can be considered not only for computing unmeasured values but for compressing the data, too. However, polynomial approaches are limited concerning their accuracy. In the last decade neural networks were applied very successfully on many fields of data mining and representation. Radial basis function (RBF) network proved to be one of the most promising type of neural network models for data approximation (Haykin, 1999). In this article, we suggest and improvement of neural network modeling in order to increase the estimation accuracy.

\section{Regression via RBF neural network}

Fig. 1 illustrates an RBF network with inputs $x, y$ and output $z$. The arrows in the figure symbolize the signal flow in the network. The RBF network consists of one hidden layer of basis functions, or neurons.

\footnotetext{
${ }^{1}$ Department of Photogrammetry and Geoinformatics, Budapest University of Technology and Economy, H-1521 Budapest, Hungary, e-mail: palancz@epito.bme.hu

${ }^{2}$ Department of Geodesy and Surveying, Budapest University of Technology and Economy, H1521 Budapest, Hungary, e-mail: lvolgyesi@epito.bme.hu
} 


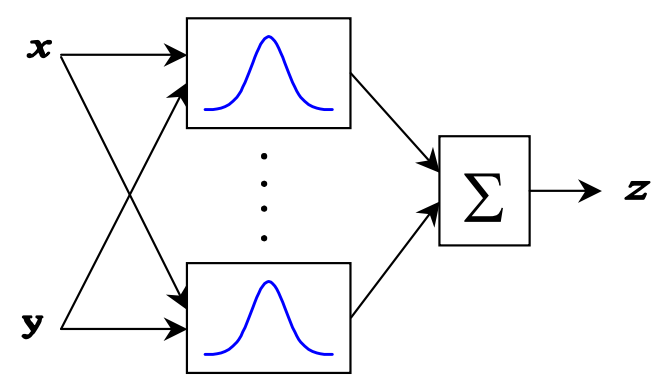

Fig. 1. An RBF network with one output

The basis function is a Gaussian bell shape curve with two parameters $\lambda, \beta$.

$$
e^{-\lambda^{2}(x-\beta)^{2}}
$$

The RBF network output is formed by a weighted sum of the neuron outputs

$$
z(x, y)=\sum_{i=1}^{n b} w_{i} e^{-\lambda 1_{i}^{2}\left(x-\beta 1_{i}\right)-\lambda 2_{i}^{2}\left(y-\beta 2_{i}\right)}
$$

where $n b$ the number of neurons. The parameters $(w, \beta, \lambda)$ are adjusted on the bases of the measured triples, called teaching set, $\left\{x_{i}, y_{i}, z_{i}, i=1, \ldots, n\right\}$ to minimize the deviation between the measured value and the network output in the least square sense during the learning process (Freeman, 1994).

Although, this technique proved to be satisfactory in most of the cases, when a surface to be estimated has very sophisticated morphology, one should improve the method.

\section{Sequence of neural networks}

In order to improve the estimation of our network, let us suppose that the learning process based on the teaching set $\left\{x_{i}, y_{i}, z_{i}: i=1, \ldots, n\right\}$ results a network $N_{1}(x, y)$. The error of this network is

$$
\varepsilon_{1}=z(x, y)-N_{1}(x, y)
$$

Then let us employ a new teaching set $\left\{x_{i}, y_{i}, \varepsilon_{1 i}: i=1, \ldots, n\right\}$ which results a new network $N_{2}(x, y)$, to estimate $\varepsilon_{1}$. The error of this network is

$$
\varepsilon_{2}=\varepsilon_{1}-N_{2}(x, y)
$$

To estimate the error of the $k$-th network, $\varepsilon_{k+1}$ in this sequence, we get

$$
\varepsilon_{k+1}=\varepsilon_{k}-N_{k+1}(x, y)
$$

It means that $m$-th order estimation of $z$ can be expressed as

$$
z(x, y)=N_{1}(x, y)+\varepsilon_{1}=N_{1}(x, y)+N_{2}(x, y)+\varepsilon_{2}=\ldots=\sum_{k=1}^{m} N_{k}(x, y)+\varepsilon_{m}
$$


Let us suppose that the relative error of the k-th order estimation using $p$ vector norm (for Euclidean norm $p=2$ ) less then 1 for every $k$ :

$$
\frac{\left|\varepsilon_{k}\right|}{\left|\varepsilon_{k-1}\right|}<1
$$

then

$$
\lim _{m \rightarrow \infty} \frac{\left|\varepsilon_{m}\right|}{|z(x, y)|}=\lim _{m \rightarrow \infty} \frac{\left|\varepsilon_{1}\right|}{|z(x, y)|} \cdot \frac{\left|\varepsilon_{2}\right|}{\left|\varepsilon_{1}\right|} \quad \ldots \frac{\left|\varepsilon_{m}\right|}{\left|\varepsilon_{m-1}\right|}=0
$$

It means that the estimation error can be reduced step by step increasing the number of terms in this sequence.

\section{Application to geoid approximation}

Considerable investigations are in progress recently in Hungary for the determination of geoid heights with a $\mathrm{cm}$ accuracy: lithospheric geoid solution (Papp and Kalmár, 1996), gravimetric solution HGR97 (Kenyeres, 1999), HGTUB98 and HGTUB2000 solution (Tóth and Rózsa, 2000; Tóth et all, 2000). The HGTUB2000 geoid heights were used for our investigations. The HGTUB2000 gravimetric solution was based on terrestrial gravity data, height data, and the EGM96 geopotential model, and was computed with the 1D Spherical FFT method (Tóth and Rózsa, 2000). Accuracy of HGTUB2000 geoid heights is about $\pm 3-4 \mathrm{~cm}$. Fig 2 shows the geoid surface in Hungary.

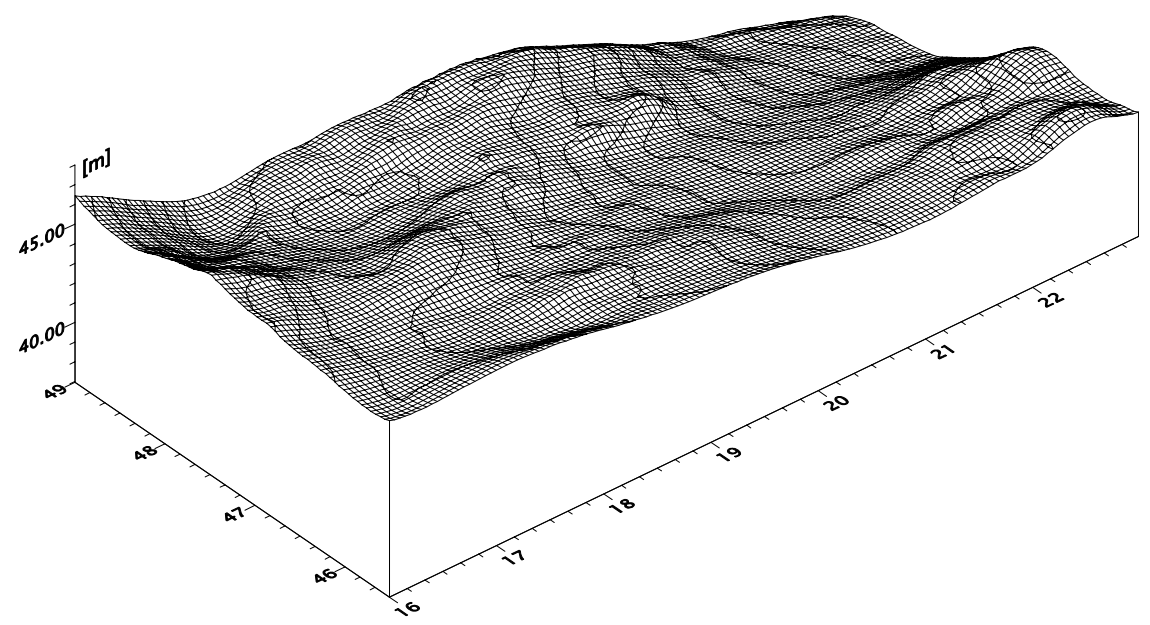

Fig. 2. The HGTUB2000 geoid surface in Hungary 
Instead of application of this huge geoid database for practical purposes we tried to find a simple mathematical formula (an equation of surface of geoid forms in Hungary). Using this mathematical formula to compute geoid heights in arbitrary points in Hungary would be more simple than using the huge geoid database for interpolating the geoid heights between known points, especially if it should be implemented in a computational procedure.

In our former investigations, polynomials were fitted to the known geoid heights of grid points, and using this polynomials geoid heights were computed for the same grid. Differences between the original and the computed values are characteristic of accuracy of geoid heights computed by polynomials. Increasing the degree of polynomials, first the accuracy was increased, then above eight degree decreased, because of the deterioration of conditions of equations. A new method was needed to look for, because the maximum accuracy resulted by applying eight degree polynomials was not enough for our purposes. That's why the possibility of applying of neural networks come out.

HGTUB2000 geoid heights were used in the area $45^{\circ} 30^{\prime} \leq \varphi \leq 49^{\circ}, 16^{\circ} \leq \lambda<$ $23^{\circ}$; the resolution of the grid was $\Delta \varphi=2{ }^{\prime} 30^{\prime \prime} \times \Delta \lambda=4$ ' $10^{\prime \prime}$. So the geoid was represented by 8484 triples, $\left\{x_{i}, y_{i}, z_{i}, i=1,2, \ldots, 8484\right\}$. To estimate the geoid, a RBF neural network has been employed with 35 neurons having Gaussian activation functions. Then further neural networks with saturated line activation function (decays linearly with the distance from the basis center) (Joberg, 2001) were used to reduce the estimation error. The network learned fairly well. The most important statistical data describing the quality of the estimation are the followings:

- Euclidean norm of the error vector, $[\mathrm{m}]$ :

$$
\left|\varepsilon_{m}\right|=\left|z(x, y)-\sum_{k=1}^{m} N_{k}(x, y)\right|
$$

- maximum error, the greatest element of the error vector in absolute value, $[\mathrm{cm}]$ :

$$
\max \left|\left(\varepsilon_{m}\right)_{i}\right|
$$

- mean value of the error vector components, $[\mathrm{m}]$ :

$$
M_{m}\left(\varepsilon_{m}\right)
$$

- standard deviation, $[\mathrm{cm}]$ :

$$
\sigma_{m}\left(\varepsilon_{m}\right)
$$

Table 1. shows these statistical values as functions of the estimation order $m$.

Tab. 1 Quality of the estimation as function of the estimation order

\begin{tabular}{ccccc}
\hline $\mathrm{m}$ & $\left|\varepsilon_{m}\right|$ & $\max \left|\left(\varepsilon_{m}\right)_{i}\right|$ & $M_{m}\left(\varepsilon_{m}\right)$ & $\sigma_{m}\left(\varepsilon_{m}\right)$ \\
\hline 1 & 0.00899 & 0.585434 & $-1.3045110^{-5}$ & 0.0976828 \\
4 & 0.00397 & 0.362296 & $-2.3580910^{-14}$ & 0.065825 \\
\hline
\end{tabular}


The histogram of the error vector components on Fig. 3 characterising also the estimation quality.
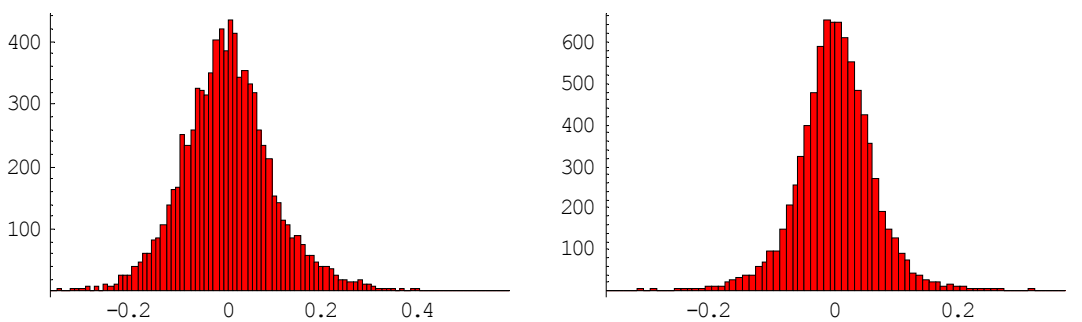

Fig. 3. Histogram of the error vector components in $[\mathrm{m}]$ in case of the first and fourth order estimation

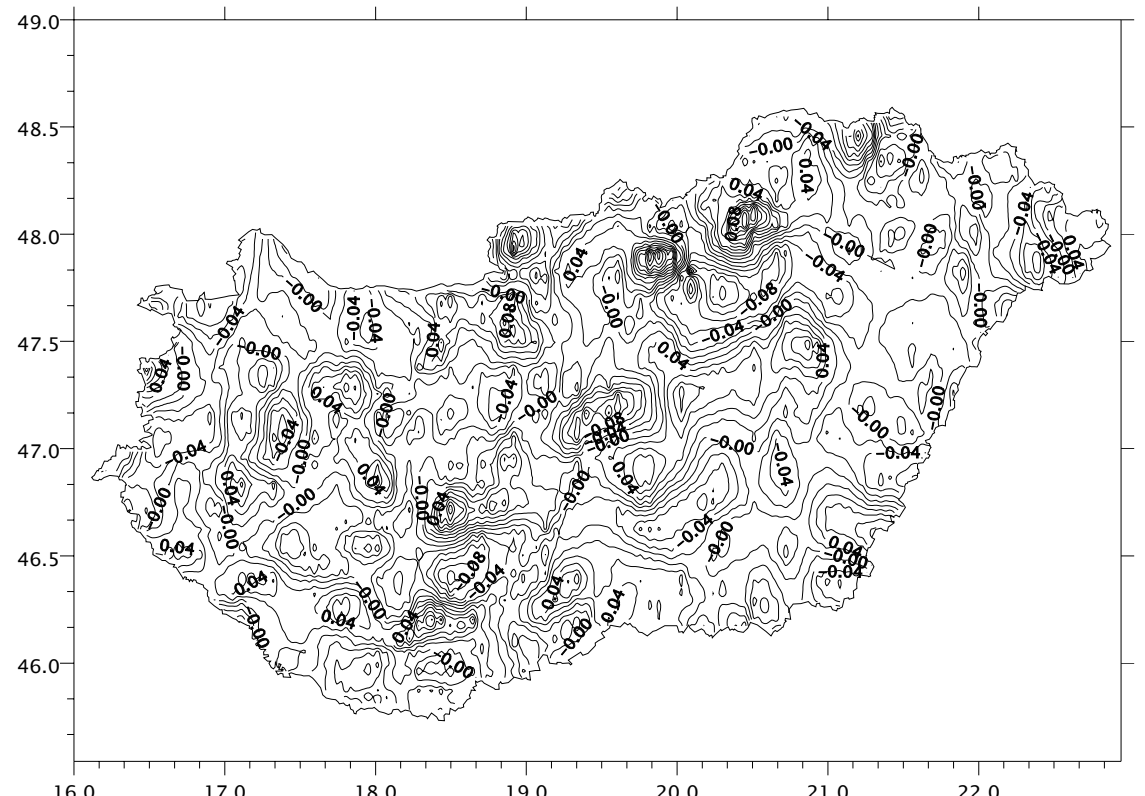

Fig. 4 Differences in $[\mathrm{m}]$ between the estimated and the original (HGTUB2000) geoid heights.

According to Fig. 4 and 5, the RBF neural model provides a very good estimation of the geoid heights, especially in the region of Hungary. The maximal error of our estimation is the same order than the error of the data to be estimated. 


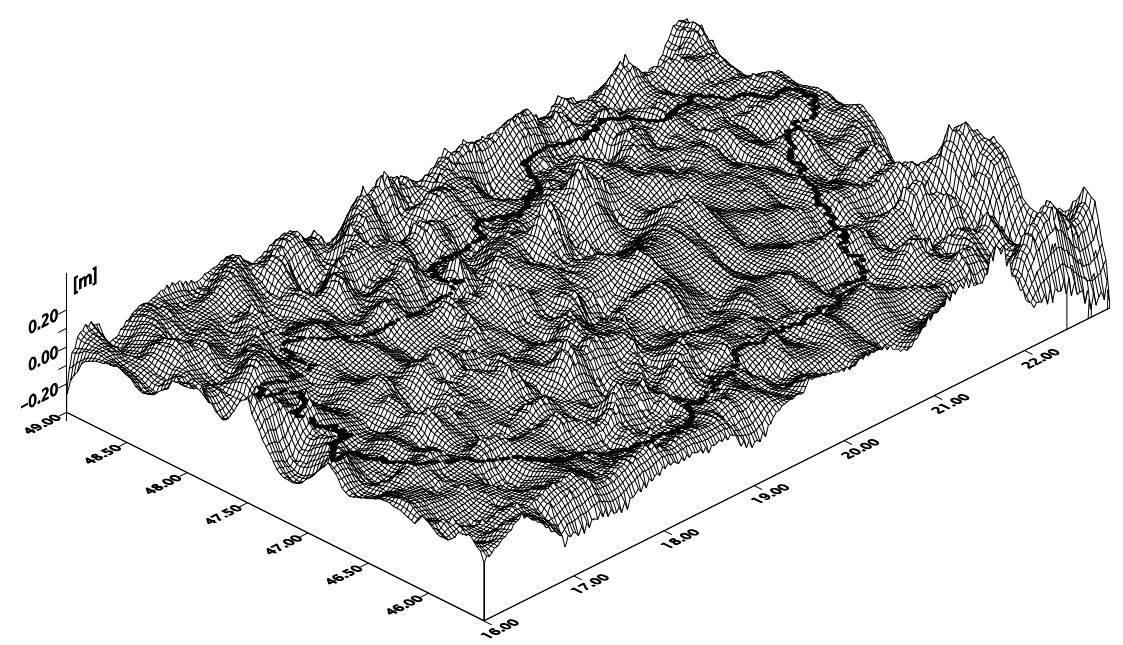

Fig. 5. Surface picture of differences between the estimated and the HGTUB2000 geoid

\section{Summary}

Employing sequence neural network technique, basically as a regression method, the estimation error can be reduced very significantly, even in the case of a morphologically so sophisticated data structure, as a geoid.

Theoretically, the proper approximation of the geoid values, which were not included in the teaching set is ensured by the thesis of Kolmogorov (Horváth 1998), however it should be verified numerically for every different problem. We employed the RBF network, because the radial basis type activation function proved to be the most efficient in case of function approximation problems (Barsi 1999 and Veres 2002). The number of neurons in the hidden layer was increased up to the value, which resulted smaller approximation error than that of the measurement data themselves. According to our experience, the iteration process is converging rapidly, and after 3-4 iteration step there was no further significant change in the values.

Using the symbolic computing capability of Mathematica, round-off error can be avoid and the structure of the RBF network may be modified much more naturally than it is possible in other neural network software tools and the result can be easily translated into high level language like C.

\section{Acknowledgement}

Our investigations were supported by the Hungarian National Research Fund (OTKA), contract No. T-030177, T-037929; and the Geodesy and Geodynamics Research Group of the Hungarian Academy of Sciences. 


\section{References}

Barsi A. 1999: Coordinate transformation by use of neural network. Geodézia és Kartográfia, Budapest, LI, No. 10. pp.12-18. (in Hungarian)

Freeman J A 1994: Simulating Neural Networks with Mathematica, Addison Wesley, New York.

Haykin I 1999: Neural Networks: A Comprehensive Foundation, Second Edition, Macmillan, New York.

Horváth G. at all 1998: Neural networks and their technical applications. Mủegyetemi Kiadó, Budapest. (in Hungarian)

Joberg S 2001: Neural Networks Package, 2001 Mathematica Developer Conference, Champain, IL, USA.

Kenyeres A 1999: Completion of the nationwide GPS-gravimetric geoid solution for Hungary. Phys. Cem. Earth (A) Vol. 24. No.1. pp. 85-90.

Papp G, Kalmár J 1996: Interpretation of local geoid undulations in the Pannonian Basin. Österreichische Beiträge zu Meteorologie und Geophysik. Proceedings of the $7^{\text {th }}$ International Meeting on Alphine Gravimetry. pp. 95-96.

Tóth Gy, Rózsa Sz 2000: New Datasets and Techniques - an Improvement in the Hungarian Geoid Sulution. Paper presented at Gravity, Geoid and Geodynamics Conference, Banf, Alberta, Canada July 31 - Aug 4, 2000.

Tóth Gy, Rózsa Sz, Andritsanos V D, Ádám J, Tziavos I N 2000: Towards a cm-Geoid for Hungary: Recent Efforts and Results. Phys. Chem. Earth (A), Vol. 25. No. 1. pp. 47-52.

Veres G. 2002: Using RBF neural network for determining altitude coordinates. Geodézia és Kartográfia, Budapest, LIV. No. 7. 25-30. (in Hungarian)

Paláncz B, Völgyesi L (2003): High accuracy data representation via sequence of neural networks. Acta Geodaetica et Geophysica Hungarica, Vol. 38, Nr. 3, pp. 337-343.

Dr. Lajos VÖLGYESI, Department of Geodesy and Surveying, Budapest University of Technology and Economics, $\mathrm{H}-1521$ Budapest, Hungary, Müegyetem rkp. 3.

Web: http://sci.fgt.bme.hu/volgyesi E-mail: volgyesi@eik.bme.hu 